\title{
Population Pharmacokinetic-Pharmacodynamic Modeling of TF-505 Using Extension of Indirect Response Model by Incorporating a Circadian Rhythm in Healthy Volunteers
}

\author{
Yoshiaki Matsumoto, ${ }^{*, a, 1)}$ Tomoe Fujita, ${ }^{b}$ Yoshimasa Ishida, ${ }^{a}$ Makiko Shimizu, ${ }^{a}$ Hiroyuki Kakuo, ${ }^{c}$ \\ Kazumasa Yamashita, ${ }^{c}$ Masataka Majima, ${ }^{b}$ and Yuji Kumagai ${ }^{b}$ \\ ${ }^{a}$ Department of Clinical Pharmacology and Toxicology, Showa Pharmaceutical University; 3-3165 Higashitamagawa- \\ gakuen, Machida, Tokyo 194-8543, Japan: ${ }^{b}$ Department of Pharmacology, School of Medicine, Kitasato University; \\ Sagamihara 228-8555, Japan: and ${ }^{c}$ Pharmacokinetics Research Laboratory, Taiho Pharmaceutical Co., Ltd.; Tokushima \\ 771-0194, Japan. Received December 9, 2004; accepted May 23, 2005; published online May 27, 2005
}

The pharmacokinetic-pharmacodynamic (PK-PD) relationship of the newly developed drug, $(-)-(S)-4-[1-$ [4-[1-(4-isobutylphenyl)butoxy]benzoyl]indolizin-3-yl]butyric acid (TF-505), was characterized via a population approach in early human study. Healthy volunteers were divided into six groups. The groups received four single doses $(25,50,75$ or $100 \mathrm{mg})$ and 2 multiple doses $(12.5$ or $25 \mathrm{mg})$ of TF-505, respectively. Dihydrotestosterone (DHT) data were collected to assess TF-505 pharmacodynamics. Population PK/PD modeling of TF-505 was performed via mixed-effects modeling using the NONMEM software package. The final PK-PD model incorporates a two-compartment PK model and an extended indirect PD model. The population PK parameters were $0.197 \mathrm{~h}^{-1}$ for the $k_{\mathrm{a}}, 0.0678 \mathrm{~h}^{-1}$ for $k_{\mathrm{e}}, 12.5 \mathrm{I}$ for $V_{\mathrm{c}}, 0.0645 \mathrm{~h}^{-1}$ for $k_{12}, 0.0723 \mathrm{~h}^{-1}$ for $k_{21}$. Extension of indirect response model by incorporating a time-dependent periodic function for $k_{\text {in }}$ takes into account the chronopharmacologic rhythms $\left(I_{\text {max }}: 0.706 \pm 0.297, \mathrm{IC}_{50}: 1.01 \pm 1.64(\mu \mathrm{g} / \mathrm{ml}), k_{\text {out }}: 0.221 \pm 0.0486\left(\mathrm{~h}^{-1}\right), R_{\mathrm{m}}: 20.4 \pm 8.08\left(\% \mathrm{~h}^{-1}\right)\right.$, $R_{\mathrm{amp}}: 5.06 \pm 3.43\left(\% \mathrm{~h}^{-1}\right), T_{\mathrm{z}}: 5.01 \pm 0.407(\mathrm{~h})($ Population mean \pm S.E. $\left.)\right) . R_{\mathrm{m}}$ is the mean DHT synthesis rate, $R_{\mathrm{amp}}$ is the amplitude of the DHT synthesis rate, and $T_{\mathrm{z}}$ is the acrophase time, signifying maximum synthesis rate. The present study represents a successful population PK-PD model using the full data from early human studies. The population parameters thus obtained could provide useful indicators for the determination of dosage regimens in exploratory studies in patient populations.

Key words TF-505; pharmacokinetic-pharmacodynamic modeling; chronopharmacologic rhythm; population; NONMEM

(-)-(S)-4-[1-[4-[1-(4-Isobutylphenyl)butoxy]benzoyl]indolizin-3-yl]butyric acid ,TF-505, is a novel nonsteroidal and non-competitive inhibitor of type I and type II $5 \alpha$-reductase. $5 \alpha$-Reductase, a nuclear membrane-bound enzyme, consists of two isozymes. Type I is expressed in extraprostatic tissues such as skin and liver and type II is detected in male accessory sex glands, prostate and liver. ${ }^{2)}$ The physiological function of $5 \alpha$-reductase is the conversion of testosterone into dihydrotestosterone (DHT). As high activities of $5 \alpha$-reductases were shown in patients with benign prostate hyperplasia ${ }^{3-5)}$ and a defect of the type II $5 \alpha$-reductase gene was associated with male pseudohermaphroditism with a small or absent prostate ${ }^{6,7)}$ it is considered that $5 \alpha$-reductases play an important role in the development of benign prostate hyperplasia. Thus, TF- 505 has been developed as a therapeutic drug for benign prostatic hyperplasia.

We have previously reported the results of tolerability and single- and multiple-dose studies of TF-505 in healthy volunteers. In that study, concentration-effect analysis of TF-505 was also carried out using an indirect response model. However, the modeling was conducted in each group of studies so that the parameters obtained from that model could not reflect those from a population, but a small size of individuals. ${ }^{8)}$ In the present study, the pharmacokinetic (PK) and pharmacodynamic (PD) data from both single- and multipledose studies were combined to evaluate parameters in the generalized population and retrospective analysis was conducted using mixed-effect modeling (NONMEM). ${ }^{9)}$ In the process of the modeling, a surrogate marker of the effect of TF-505, an inhibition of plasma DHT levels, tended to increase $4 \mathrm{~h}$ after administration of TF-505 in all single-dose studies. In our simulation based on the present model, plasma DHT levels reached to a maximum level in the early evening and declined with time. In addition, there has been reported a circadian rhythm in plasma levels of DHT. ${ }^{10,11)}$ Therefore, the present study used the $E_{\max }$ model with an extended indirect response model by incorporating a circadian rhythm in order to fit the model to the data.

Population PK-PD studies and modeling are considered useful in drug development for assessment of efficacy/safety in relation to drug plasma concentrations and defining an optimum dosage regimen in the target population. Many population PK-PD analysis studies have been reported during the development of drugs such as an antineoplastic ${ }^{12)}$ an anesthetic, ${ }^{13)}$ a lactate reducing agent, ${ }^{14)}$ a platelet inhibitor, ${ }^{15)}$ a thrombin inhibitor, ${ }^{16)}$ and a 11- $\beta$-hydroxysteroid dehydrogenase inhibitor. ${ }^{17)}$ Although such population approaches in clinical trials are mostly performed on the patient population, some studies were also performed on healthy volunteers in phase I studies. ${ }^{14-17)}$ The aim of the present study was to define the population PK-PD model of TF-505 in an early human study. The parameters thus obtained would more reflect population mean than those obtained from the previous study.

\section{MATERIALS AND METHODS}

Volunteers and Study Design Thirty-six healthy male Japanese volunteers participated in this study. They were divided into six study groups, 6 adults males/group. Table 1 summarizes the subject population. The first to the fourth groups participated in the single-dose studies of TF-505, and 
Table 1. Demographic Data of the Subject in the Present meta-Analysis

\begin{tabular}{|c|c|c|c|c|c|c|}
\hline & \multicolumn{4}{|c|}{ Single-dose } & \multicolumn{2}{|c|}{ Multiple-dose } \\
\hline & $25 \mathrm{mg}$ & $50 \mathrm{mg}$ & $75 \mathrm{mg}$ & $100 \mathrm{mg}$ & $12.5 \mathrm{mg}$ & $25 \mathrm{mg}$ \\
\hline$n$ & 6 & 6 & 6 & 6 & 6 & 6 \\
\hline $\begin{array}{l}\text { Age } \\
\text { (year) }\end{array}$ & $\begin{array}{c}22.8 \pm 2.9 \\
(20-28)\end{array}$ & $\begin{array}{c}25.2 \pm 2.5 \\
(22-29)\end{array}$ & $\begin{array}{r}48.8 \pm 5.9 \\
(40-56)\end{array}$ & $\begin{array}{r}45.3 \pm 2.0 \\
(43-48)\end{array}$ & $\begin{array}{c}52.5 \pm 8.3 \\
(40-61)\end{array}$ & $\begin{array}{c}48.8 \pm 9.1 \\
(40-64)\end{array}$ \\
\hline Body weight & $61.1 \pm 6.7$ & $61.1 \pm 9.5$ & $61.6 \pm 7.9$ & $65.7 \pm 5.0$ & $61.6 \pm 9.1$ & $64.9 \pm 5.7$ \\
\hline$(\mathrm{kg})$ & $(53.8-72.2)$ & $(50.1-71.3)$ & $(52.0-71.3)$ & $(58.7-72.0)$ & $(49.6-72.3)$ & $(54.9-71.0)$ \\
\hline
\end{tabular}

Mean \pm S.D. (range).

the fifth and sixth groups in the multiple-dose studies. The first group received $25 \mathrm{mg}$ of TF-505. The second group received $50 \mathrm{mg}$ of TF-505. The third and fourth groups consisted of men over 40 years of age. The third group received a single dose of $75 \mathrm{mg}$ of TF-505, and the fourth group received a single dose of $100 \mathrm{mg}$ of TF-505. The fifth group received repeated doses of $12.5 \mathrm{mg}$ of TF-505, and the sixth group was treated with repeated doses of $25 \mathrm{mg}$ of TF- 505 .

The inclusion criteria were as follows: (1) Males had to be aged $\geq 20$ years at entry into the low single-dose studies ( 25 and $50 \mathrm{mg}$ of TF-505) and $\geq 40$ years for the high singledose and multiple-dose studies. (2) Body weight had to be within $\pm 20 \%$ of the ideal body weight which was calculated from the equation $\{[$ height $(\mathrm{cm})-100] \times 0.9\}$. Smoking was not considered an exclusion criterion. Smoking subjects were directed to stop smoking for $24 \mathrm{~h}$ after administration of the test drug, and the subjects could not smoke within a period of $1 \mathrm{~h}$ before sampling their blood at 48 and $72 \mathrm{~h}$ after the single dose administration. In the multiple-dose studies, smoking was prohibited for $24 \mathrm{~h}$ after the $1 \mathrm{st}$ and $7 \mathrm{th}$ dose. The subjects were also not allowed to take any medication from 1 week before the study to the end of the study and to have drinks containing caffeine, alcohol or grapefruit during hospitalization.

In the single-dose studies, each of the 4 groups of 6 subjects received $25,50,75$ or $100 \mathrm{mg}$ of TF-505 at 9 a.m. without breakfast. The other 2 groups of 6 subjects received 12.5 and $25 \mathrm{mg}$ of TF-505, respectively, once daily after breakfast at 9 a.m. for $7 \mathrm{~d}$.

The study was conducted at the Clinical Investigation Center of Kitasato University East Hospital following the approval by the Institutional Review Board. All subjects gave their written informed consent to participate in the study.

Blood Sampling Single-dose study: Blood samples were collected for the TF-505 assay at $0,1,2,3,4,6,8,10,12,24$, 48 and $72 \mathrm{~h}$, and for the DHT assay at $0,4,8,12,24,48$ and $72 \mathrm{~h}$ after single administration.

Multiple-dose study: Blood samples were collected for the TF-505 assay at $1,2,3,4,6,8,10$ and $12 \mathrm{~h}$ after drug administration on day 1 , and $1,2,3,4,6,8,10,12,24,48$ and $72 \mathrm{~h}$ after drug administration on day 7 . Blood samples were collected for the DHT assay $12 \mathrm{~h}$ before and just prior to the administration of the first dose, $12 \mathrm{~h}$ after administration during the multiple-dose study, and at 24,48 and $72 \mathrm{~h}$ after the final dose.

Analytical Assay Blood samples were collected and centrifuged at $1500 \times \boldsymbol{g}$ for $15 \mathrm{~min}$ at $4{ }^{\circ} \mathrm{C}$. The plasma was separated and stored at $-20^{\circ} \mathrm{C}$ until analysis.

Plasma concentrations of TF- 505 were measured by re- versed phase HPLC coupled with ion spray tandem mass spectrometry (LC/MS/MS) at Taiho Pharmaceutical Co., Ltd., as described previously. ${ }^{18)}$ Intra- and inter-assay coefficients of variation were below $15 \%$. The limit of quantification was set at $1.0 \mathrm{ng} \mathrm{ml}^{-1}$. Plasma DHT concentrations were measured by radioimmunoassay as described previously. ${ }^{19)}$ The limit of quantification was set at $50 \mathrm{pg}$ tube ${ }^{-1}$ with intraand inter-assay coefficients of variation below 20 and $25 \%$, respectively. Taking into account the circadian rhythm-related changes in plasma DHT concentrations, ${ }^{10,11)}$ values after administration of TF-505 were compared to those at the same times before administration (basal values). Changes in plasma DHT concentrations were expressed as percentages of the basal values.

Pharmacostatistical Models Analysis of data was carried out using the computer software package NONMEM, Version 5, Level 1.1 for nonlinear mixed-effects modeling. ${ }^{9)}$ Mixed-effect modeling allows the simultaneous analysis of data from multiple individuals while maintaining the correlation of observations for a given individual. Totally, 564 measured points of plasma TF-505 concentration and 264 measured point of plasma DHT concentration for the 36 subjects were employed in the analysis. The concentration data of all individuals were identified for each individual and classified. The first-order method conditional method (FOCE) implemented in NONMEM was used for PK and PK-PD model development. Model selection was based on extended least squares method (the maximum likelihood objective function). The objective function value of NONMEM is approximately $\chi^{2}$ distributed. With 1 degree of freedom, a decrease of 3.84 corresponds to a critical value of $\alpha=0.05$. Intra- and inter-individual variances for all $\mathrm{PK}$ and $\mathrm{PD}$ parameters were modeled assuming a lognormal distribution. All of PK and PD parameters were assumed linearly independence.

Pharmacokinetic-Pharmacodynamic Model The PK model was estimated using one- or two-compartment model with first-order absorption or Michaelis-Menten type saturable absorption, and first-order elimination.

The base PK-PD structure model consisted of the final PK model and the indirect response model with input inhibition. ${ }^{20,21)}$ This choice was based on the mechanism of TF-505 which inhibits synthesis of DHT via an inhibition of testosterone metabolizing enzyme. Additionally, Extension of indirect response model by incorporating a time-dependent periodic function for $K_{\text {in }}$ takes into account the chronopharmacologic rhythms. PK parameters were fixed to values estimated from the final PK model. 


\section{RESULTS}

Pharmacokinetic and Pharmacodynamic Model Following single p.o. administration, the time to peak concentration $\left(T_{\max }\right)$ were $4.38 \pm 1.01,5.47 \pm 2.34,4.23 \pm 0.86$ and $3.85 \pm 0.73 \mathrm{~h}$ (mean \pm S.D.) after administration of $25,50,75$ or $100 \mathrm{mg}$ of TF-505. Peak concentrations were $1.10 \pm 0.38$, $2.45 \pm 0.70,3.79 \pm 1.92$ and $3.12 \pm 1.20 \mu \mathrm{g} / \mathrm{ml}$. The areas under the concentration-time curve $\left(A U C_{0-72}\right)$ were $32.12 \pm$ $14.46,76.95 \pm 15.96,97.50 \pm 46.82$ and $73.22 \pm 26.74 \mu \mathrm{g} \cdot \mathrm{h} /$ $\mathrm{ml}$. Although preliminary noncompartmental analysis revealed saturable $A U C$ and $C_{\max }$ in $100 \mathrm{mg}$ dose of TF-505, the predicted values were overestimated by application of Michaelis-Menten type absorption and the observed values correlated well with the predicted values when first-order absorption was applied to the model. Thus, a two-compartment model with first-order absorption, and first-order elimination was selected as the final PK model for subsequent development of the PK-PD models for TF-505 (Table 2).

Plotting DHT data against TF-505 concentrations revealed a hysteresis relationship in Fig. 1. Each step in the building of the population PK-PD model of TF-505 is shown in Table 3. The indirect PD model was found to describe the data better than the other basic PK-PD models (Eq. 1).

$$
\frac{d \mathrm{DHT}}{d T}=k_{\text {in }} \cdot\left(1-\frac{I_{\max } \times C_{\mathrm{p}}}{\mathrm{IC}_{50}+C_{\mathrm{p}}}\right)-k_{\text {out }} \cdot \text { DHT }
$$

where DHT is the response variable, $k_{\text {in }}$ is a zero-order rate constant for the onset of decrease in plasma DHT concentrations, $C_{\mathrm{p}}$ is the plasma drug concentration, $\mathrm{IC}_{50}$ is the plasma drug concentration that produces $50 \%$ of maximum inhibi-

Table 2. Development PK Models for TF-505

\begin{tabular}{ccccc}
\hline \hline & \multicolumn{3}{c}{ Model description } \\
\cline { 2 - 3 } PKodel & Absorption & Elimination & $\begin{array}{c}\text { Number of } \\
\text { compertment }\end{array}$ & \\
\cline { 2 - 4 } & & & 1 & -521.047 \\
1 & First-order & First-order & 1 & -560.515 \\
3 & First-order & First-order & 2 & -522.423 \\
4 & Michaelis-Menten type & First-order & 1 & -561.047 \\
\hline
\end{tabular}

a) Objective function.

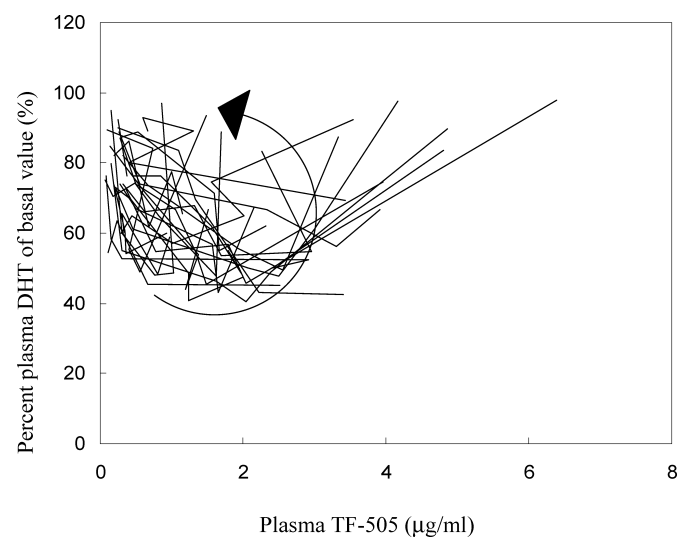

Fig. 1. Relationship between Plasma Concentrations of TF-505 and Those of DHT Levels Following Single Oral Administration at Doses of 25, 50, 75 and $100 \mathrm{mg}$ to Healthy Volunteers tion achieved at the effect site and $I_{\max }$ is the maximum fractional ability of the TF-505 to affect the $k_{\text {in }}$ process. $k_{\text {out }}$ is a first-order rate constant for the increase in plasma DHT concentrations.

Since the basic indirect PD model was not capturing the early data very well, $k_{\text {in }}$ was redefined as follows for circadian rhythm.

$$
K_{\mathrm{in}}=R_{\mathrm{m}}+R_{\mathrm{amp}} \cdot \cos \left(2 \cdot \pi\left(T-T_{\mathrm{z}}\right) / 24\right)
$$

where $R_{\mathrm{m}}$ is the mean DHT synthesis rate, $R_{\mathrm{amp}}$ the amplitude of the DHT synthesis rate, and $T_{\mathrm{z}}$ the acrophase time, signifying maximum synthesis rate. This method assumes that $T_{\mathrm{z}}$ is less than 24 and $R_{\mathrm{m}}$ is less than $R_{\mathrm{amp}}$.

Population PK and PK-PD parameters and inter- and intra-individual variability estimated from the final model are summarized in Table 4. The population mean values were $0.197 \mathrm{~h}^{-1}$ for the absorption rate constant $\left(k_{\mathrm{a}}\right), 0.0678 \mathrm{~h}^{-1}$ for the elimination constant $\left(k_{\mathrm{e}}\right), 12.51$ for the volume of distribution of central compartment $\left(V_{c}\right), 0.0645 \mathrm{~h}^{-1}$ for the rate constant $k_{12}, 0.0723 \mathrm{~h}^{-1}$ for the rate constant $k_{21}, 1.01$ $\mu \mathrm{g} \mathrm{ml}^{-1}$ for $\mathrm{IC}_{50}, 0.221 \mathrm{~h}^{-1}$ for $k_{\text {out }}, 20.4 \% \mathrm{~h}^{-1}$ for $R_{\mathrm{m}}, 5.06 \%$ $\mathrm{h}^{-1}$ for $R_{\text {amp }}, 5.01 \mathrm{~h}$ for $T_{\mathrm{z}}$ and 0.706 for $I_{\max }$. The inter-individual variabilities were $16.70 \%$ for $k_{\mathrm{a}}, 21.93 \%$ for $k_{\mathrm{e}}$,

\begin{tabular}{|c|c|c|c|}
\hline $\begin{array}{l}\text { PD } \\
\text { model }\end{array}$ & Model description & $\begin{array}{c}\text { Number of } \\
\text { parameter }\end{array}$ & $\mathrm{Obj}^{a)}$ \\
\hline 1 & $\begin{array}{l}\text { The indirect response modelling } \\
\text { with inhibition of input }\end{array}$ & 3 & 1703.638 \\
\hline 2 & $\begin{array}{l}\text { The indirect response modelling } \\
\text { with inhibition of input and Hill } \\
\text { coefficient }\end{array}$ & 4 & 1702.235 \\
\hline 3 & $\begin{array}{l}\text { The indirect response modelling } \\
\text { with inhibition of input. } K_{\text {out }} \\
\text { depend on } K_{\text {in }}\end{array}$ & 2 & 1708.957 \\
\hline 4 & $\begin{array}{l}\text { The indirect response modelling } \\
\text { with inhibition of input and Hill } \\
\text { coefficient. } K_{\text {out }} \text { depend on } K_{\text {in }}\end{array}$ & 3 & 1713.340 \\
\hline 5 & $\begin{array}{l}\text { The indirect response modelling } \\
\text { with inhibition of circadian } \\
\text { rhythm input }\end{array}$ & 5 & 1689.862 \\
\hline
\end{tabular}

Table 3. Development PD Models for TF-505

a) Objective function.

Table 4. Final Population Pharmacokinetic/Pharmacodynamic Parameters

\begin{tabular}{lcc}
\hline \hline Parameters & $\begin{array}{c}\text { Population mean } \\
\text { Value } \pm \text { S.E.M. }\end{array}$ & $\begin{array}{c}\text { Inter-individual variability } \\
\text { Value } \pm \text { S.E.M. }\end{array}$ \\
\hline$k_{\mathrm{a}}\left(\mathrm{h}^{-1}\right)$ & $0.197 \pm 0.0361$ & $0.0279 \pm 0.0226$ \\
$k_{\mathrm{e}}\left(\mathrm{h}^{-1}\right)$ & $0.0678 \pm 0.0117$ & $0.0481 \pm 0.0317$ \\
$V_{\mathrm{c}}(\mathrm{l})$ & $12.5 \pm 2.26$ & $0.0180 \pm 0.0192$ \\
$k_{12}\left(\mathrm{~h}^{-1}\right)$ & $0.0645 \pm 0.0218$ & $0.0106 \pm 0.133$ \\
$k_{21}\left(\mathrm{~h}^{-1}\right)$ & $0.0723 \pm 0.0130$ & $0 \mathrm{FIXED}^{a)}$ \\
$\mathrm{IC}_{50}(\mu \mathrm{g} / \mathrm{ml})$ & $1.01 \pm 1.64$ & $0 \mathrm{FIXED}^{a)}$ \\
$k_{\text {out }}\left(\mathrm{h}^{-1}\right)$ & $0.221 \pm 0.0486$ & $0.000525 \pm 0.0212$ \\
$R_{\mathrm{m}}\left(\% \mathrm{~h}^{-1}\right)$ & $20.4 \pm 8.08$ & $0.0117 \pm 0.0262$ \\
$R_{\mathrm{amp}}\left(\% \mathrm{~h}^{-1}\right)$ & $5.06 \pm 3.43$ & $0 \mathrm{FIXED}^{a}$ \\
$T_{\mathrm{z}}(\mathrm{h})$ & $5.01 \pm 0.407$ & $0.00700 \pm 0.0151$ \\
$I_{\max }$ & $0.706 \pm 0.297$ & $0.00541 \pm 0.0134$ \\
$\mathrm{Intra-individual} \mathrm{residual} \mathrm{variability}$ & \\
$\mathrm{PK} \sigma^{2}$ & $0.191 \pm 0.0226$ & \\
$\mathrm{PD} \sigma^{2}$ & $0.0419 \pm 0.00664$ & \\
\end{tabular}

a) Fixed at zero due to small variance estimates. 


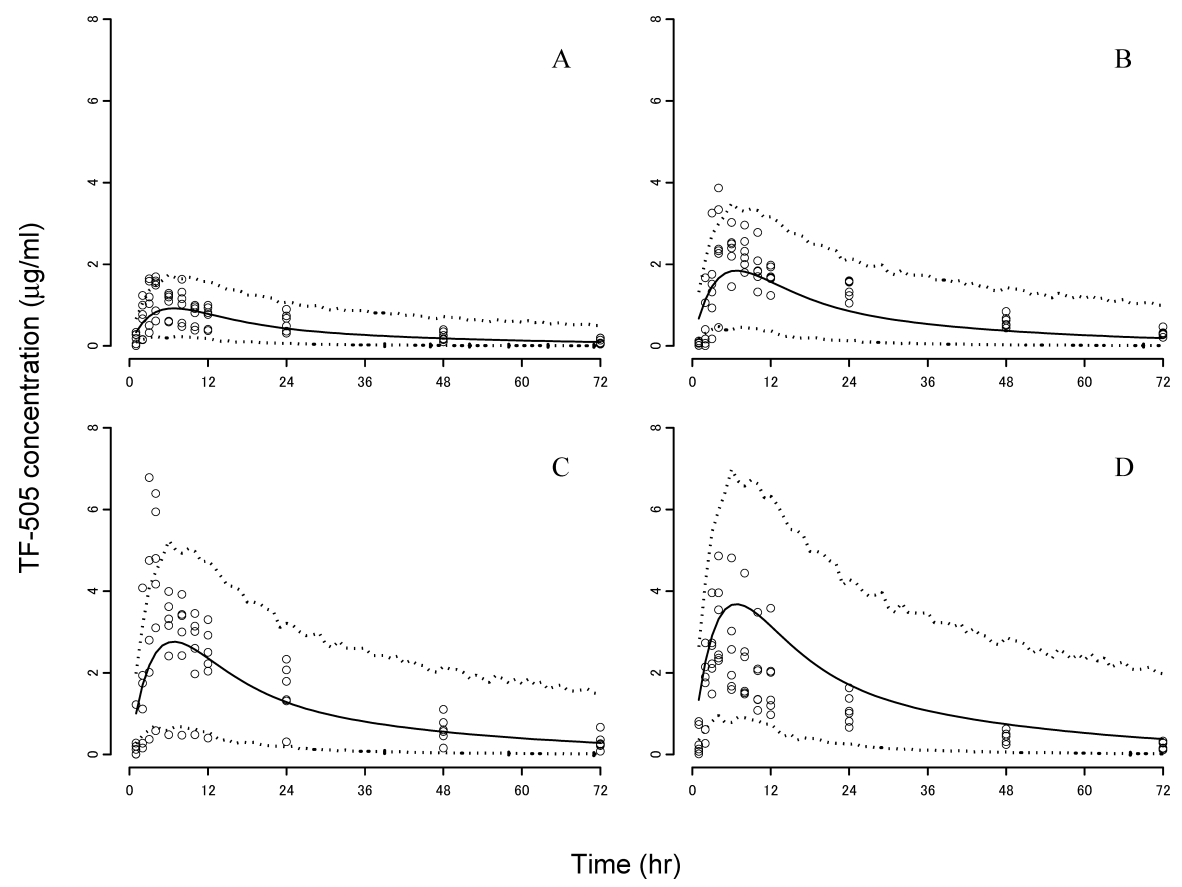

Fig. 2. The Plots of Plasma TF-505 Concentration Following Single Oral Administration Doses of 25 (A), 50 (B), 75 (C) and 100 (D) mg to Healthy Volunteers

The solid line represent predicted curve based on fixed effect parameters. The broken lines represent 5 th percentiles and 95th percentiles of 1000 times simulation by using population PK parameters.
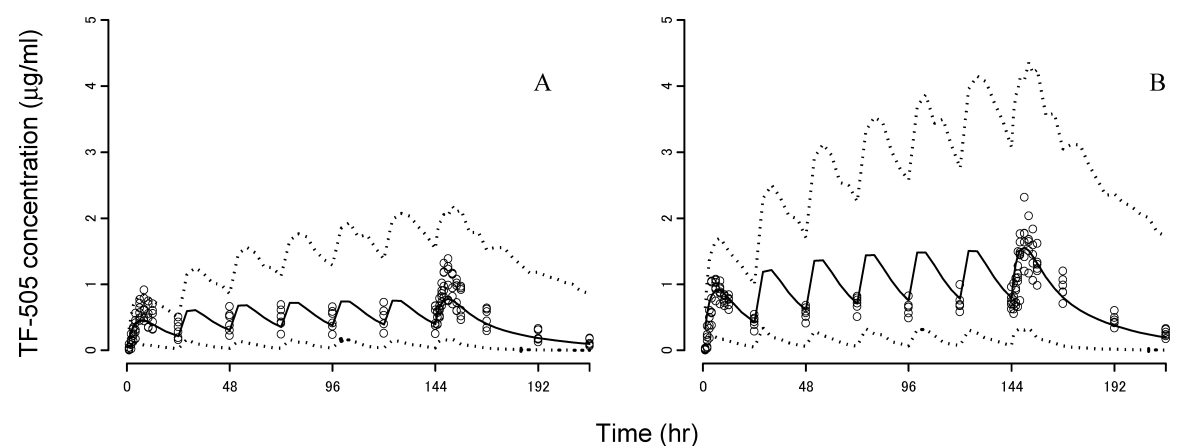

Fig. 3. The Plots of Plasma TF-505 Concentration Following Oral Administration of 12.5 (A) and 25 (B) mg Once Daily for $7 \mathrm{~d}$ to Healthy Volunteers The solid line represent predicted curve based on fixed effect parameters. The broken lines represent 5 th percentiles and 95 th percentiles of 1000 times simulation by using population PK parameters.

$13.42 \%$ for $V_{\mathrm{c}}, 10.30 \%$ for $k_{12}, 2.29 \%$ for $k_{\text {out }}, 10.82 \%$ for $R_{\mathrm{m}}, 8.37 \%$ for $T_{\mathrm{z}}$ and $7.36 \%$ for $I_{\max }$. The intra-individual variabilities were $43.70 \%$ for PK and $20.47 \%$ for PD. Interindividual variability of $k_{21}$, Ramp and $\mathrm{IC}_{50}$ were fixed at zero due to small variance estimate $\left(<10^{-8}\right)$ in preliminary analysis. Observed plasma TF-505 concentration and 5th/95th percentiles of 1000 times simulation are shown in Figs. 2 and 3. The goodness of the fit of the data including population and individual predictions versus observed concentrations of TF505 , as well as individual weighted residuals versus individual weighted residuals over time, are presented in Figs. 4 and 5 .

\section{DISCUSSION}

Previous studies performed simultaneous PK-PD modeling for TF- $505^{8)}$ and FK-143, another $5 \alpha$-reductase inhibitor, in healthy volunteers. ${ }^{22)}$ In the former study, data from each single- $(25,50,75$ or $100 \mathrm{mg})$ or multiple-dose (12.5 or 25 $\mathrm{mg}$ ) group was analyzed individually, and in the latter study all of the data from the single-dose groups (100, 200 and 500 $\mathrm{mg}$ ) was analyzed together. On the other hand, the present study demonstrated population PK-PD modeling for TF-505 using all of the data from single- and multiple-dose groups. Serum protein binding rates were constant within the ranges of 0.3 to $3 \mu \mathrm{g} / \mathrm{ml}$ of TF-505 in the in vitro study (unpublished data). The $C_{\max }$ value for $100 \mathrm{mg}$ dose of TF-505 was shown to be $3.12 \mu \mathrm{g} / \mathrm{ml}$, which seemed to give a constant protein binding rate. Accordingly, saturation of the protein binding may not be a cause of the saturable $A U C$ and $C_{\max }$, rather this may account for saturation of drug absorption as discussed in the previous study. ${ }^{8}$ )

Hysteresis loops were observed following a single administration of TF-505 (Fig. 1), where the maximum effect was observed at a time later than $T_{\max }$. These observations might result from the indirect action of TF-505 on suppression of 

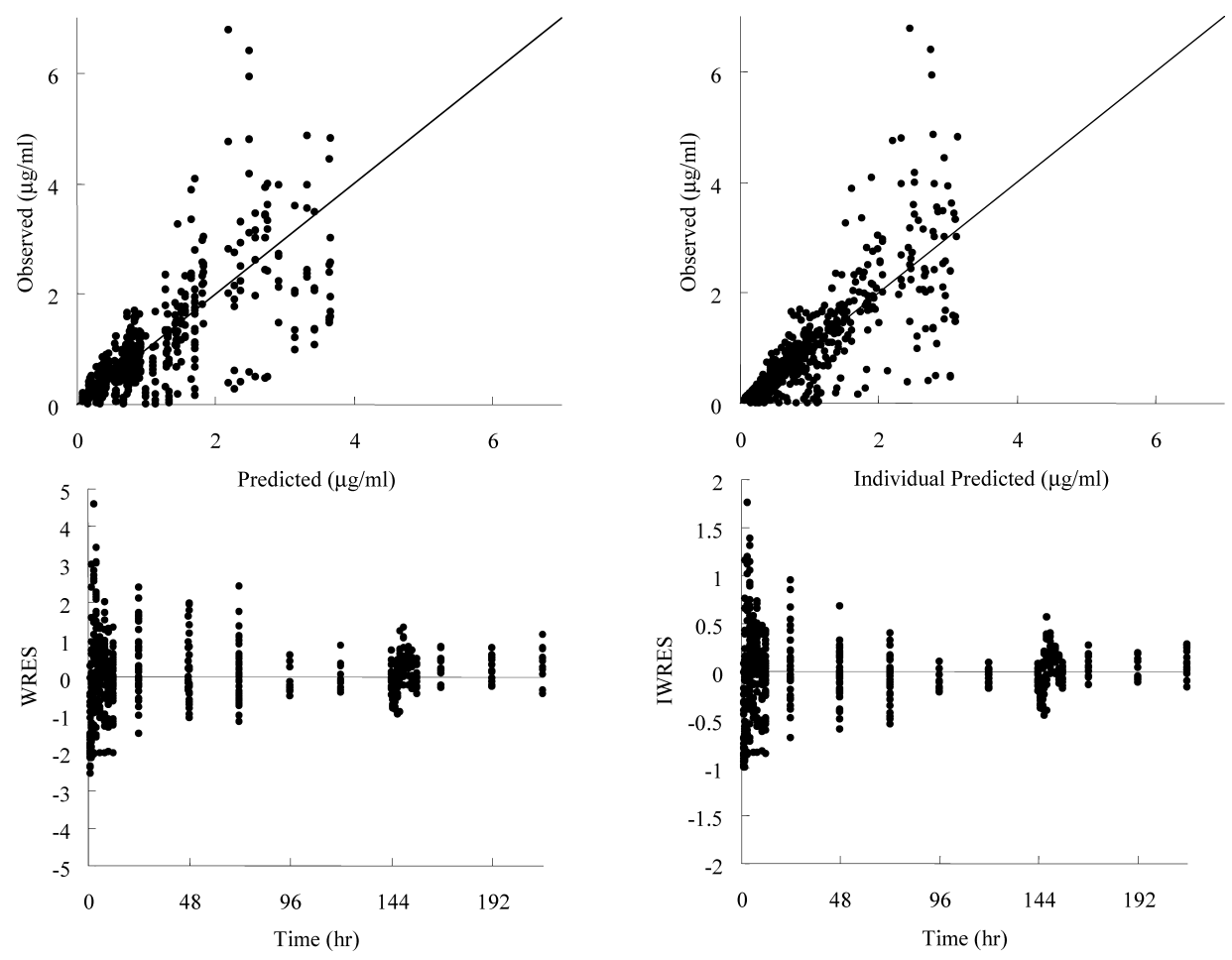

Fig. 4. The Observed TF-505 Concentration versus the Population Predictions and Individual Predictions, and Weighted Residuals (WRES) and Individual Weighted Residuals (IWRES) versus Time Since First Dose From Final PK Model
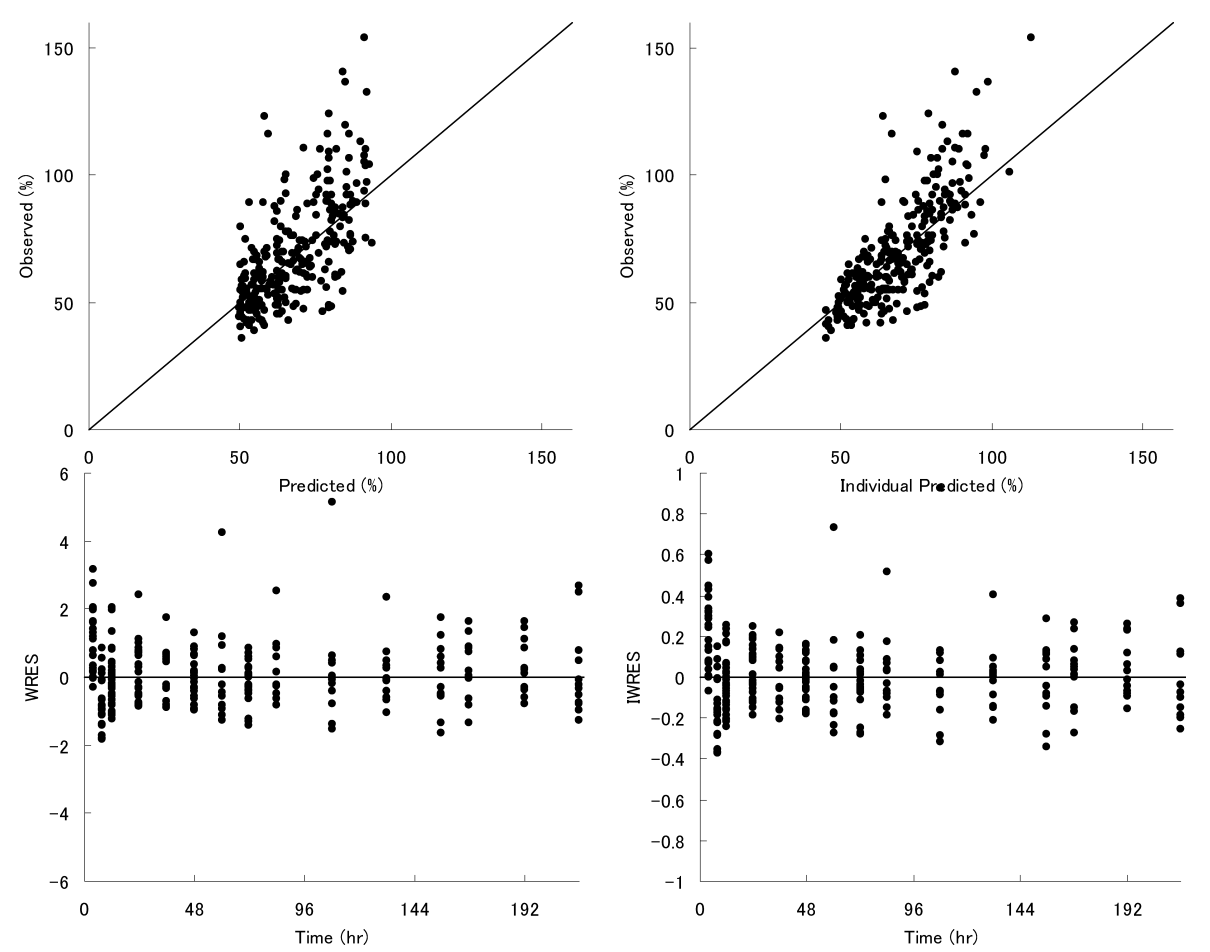

Fig. 5. The Observed Percent Plasma DHT of Basal Value versus the Population Predictions and Individual Predictions, and Weighted Residuals (WRES) and Individual Weighted Residuals (IWRES) versus Time Since First Dose from Final PD Model

DHT production, rather than from equilibrium delays in the distribution of TF-505 to the effect sites from the circulating blood. $^{23)}$ This was also supported by previous results of PK and PD analyses using indirect response modeling. ${ }^{8}$ Furthermore, circadian rhythm in plasma levels of DHT was reported in healthy men: the peak time of DHT occurred in the early evening. ${ }^{10,11)}$ In fact, some of \% DHT levels at $4 \mathrm{~h}$ were higher concentrations than baseline DHT levels in spite of administration of TF-505 (Fig. 6). Based on the fitting of final PK-PD model, $k_{\text {in }}$ reach to a maximum at 2:00 p.m. and DHT reach to a maximum concentration at $5 \mathrm{p} . \mathrm{m}$. following placebo administration. It thus appears that the basic indirect 


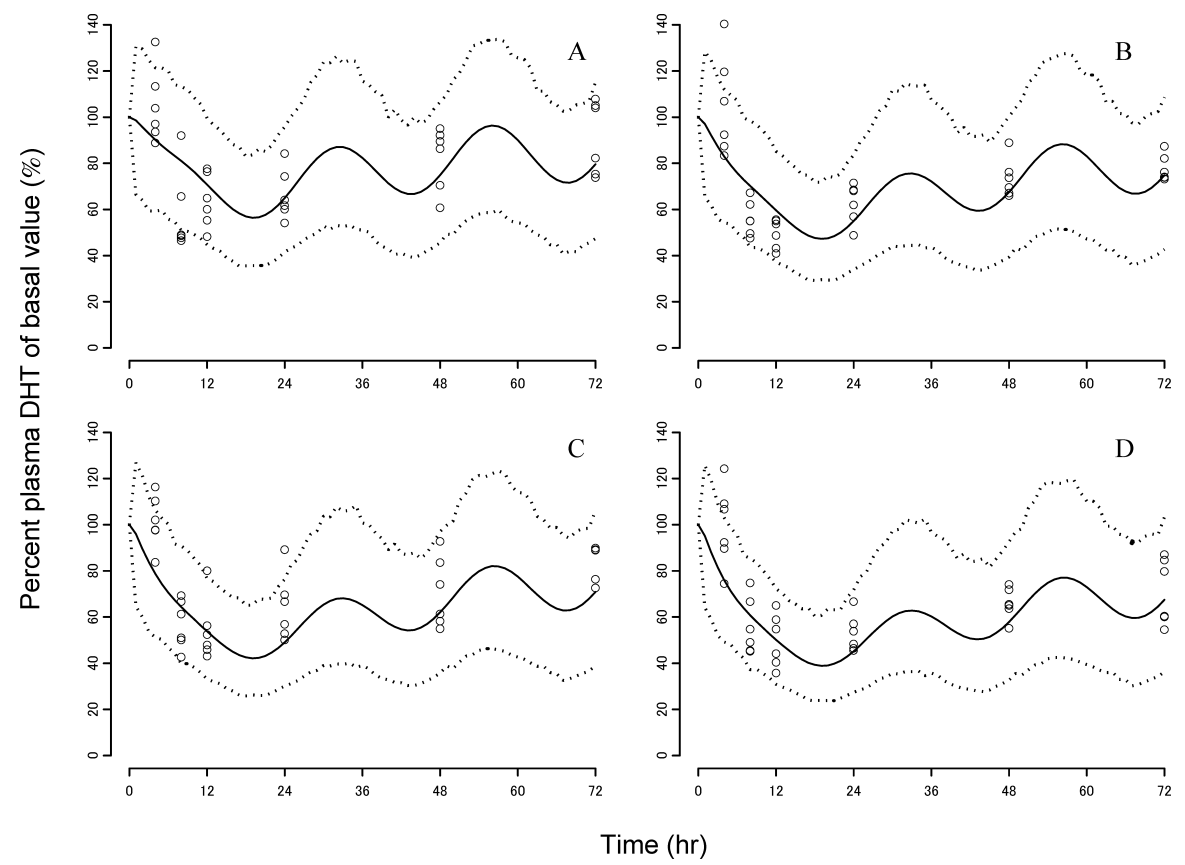

Fig. 6. The Plot of Percent Plasma DHT of Basal Value Following Single Oral Administration Doses of 25 (A), 50 (B), 75 (C) and 100 (D) mg to Healthy Volunteers

The solid line represent predicted curve based on fixed effect. The broken lines represent 5 th percentiles and 95 th percentiles of 1000 times simulation by using population mean parameters.

PD model was not capturing the early data very well. The pattern of DHT in a day was asymmetric and there is the need to convert the observed time pattern, e.g., single cosine into the input rate. ${ }^{24)}$ Thus, the mechanistic model of TF-505 PK-PD model incorporated a two-compartment model with first-order absorption, first-order elimination and extension of indirect response model by incorporating a circadian rhythm for $k_{\text {in }}$.

Gisleskog et al. reported a validated population PK-PD model of a dual $5 \alpha$-reductase inhibitor, GI198745, which inhibits not only $5 \alpha$-reductase type 2 but also type 1 for the turnover of DHT in the single dose study. ${ }^{25)}$ They used an indirect response model taking into account relative capacity of $5 \alpha$-reductase isozymes and rates of inhibition of both types of $5 \alpha$-reductase. In that study, simulations showed that GI198745 can block $5 \alpha$-reductase type 2 by $80 \%$, whereas type 1 is unaffected, giving a suppression of plasma DHT by $70 \% .{ }^{25)}$ As shown by the in vitro study, inhibitory potency of TF- 505 to $5 \alpha$-reductase type 1 is comparable to that of GI198745; $K_{\mathrm{i}}$ values of TF-505 and GI198745 for $5 \alpha$-reductase type 1 were 13.9 (unpublished data) and $6 \mathrm{~nm}^{26}{ }^{26}$ respectively. Accordingly, suppression of the plasma DHT levels observed after TF-505 administration was assumed to be mostly attributed by inhibition of $5 \alpha$-reductase type 2 . Thus, it was considered that the present study does not need to take into account the above model proposed by Gisleskog et al. for PK-PD modeling. Less potent inhibitory effect of TF505 on the plasma DHT levels compared with that of GI198745 might be due to the less affinity of TF- 505 to $5 \alpha$ reductase type $2 ; K_{\mathrm{i}}$ values of TF-505 and GI198745 for $5 \alpha$ reductase type 2 were 49.0 (unpublished data) and $7 \mathrm{~nm},{ }^{26)}$ respectively.

In the results of population PK-PD modeling, lower interindividual variabilities of $k_{\text {out }}$ and $\mathrm{IC}_{50}$ were obtained com- pared with the previous PK-PD modeling preformed on single and multiple studies. The $\mathrm{IC}_{50}$ value $(1.01 \mu \mathrm{g} / \mathrm{ml}$, $1973.97 \mathrm{~nm}$ ) obtained from the present study after applying the unbound fraction $(0.04 \%, 78.96 \mathrm{~nm})$ was close to $K_{\mathrm{i}}$ for $5 \alpha$-reductase type $2(49.0 \mathrm{nM})$. This result is consistent with that reported by Gisleskog et al. described above where GI198745, a dual $5 \alpha$-reductase inhibitor like TF-505, inhibited plasma DHT mainly through the inhibition of $5 \alpha$-reductase type $2{ }^{25)}$ The $k_{\text {out }}$ value $\left(0.221 \mathrm{~h}^{-1}\right)$, reflecting a recovery rate of plasma DHT, obtained from the present study was shown to be almost same as those of other dual $5 \alpha$-reductase inhibitors, GI198745 $\left(0.393 \mathrm{~h}^{-1}\right)$ and finasteride $(0.280$ $\left.\mathrm{h}^{-1}\right)^{25,27)}$ Therefore, it suggested that extension of indirect response model might be more physiological model than basic indirect response model and the parameters including $\mathrm{IC}_{50}$ and $k_{\text {out }}$ obtained from the present study were considered to be physiologically valid.

Accordingly, the $\mathrm{IC}_{50}$ value of TF-505 indicates the concentration that causes the maximum effect of the drug. In the previous study, multiple-dosing of TF-505 at 12.5 and $25 \mathrm{mg}$ gave average $C_{\max }$ values of 0.97 and $1.60 \mu \mathrm{g} / \mathrm{ml}$ after the 7 th dose. ${ }^{8)}$ Considering the average $\mathrm{IC}_{50}$ value of $1.01 \mu \mathrm{g} / \mathrm{ml}$ determined in the present study, it was suggested that multipledosing of TF-505 at $25 \mathrm{mg}$ would have a maximal effect on plasma DHT levels. In this study, the maximum effect of TF505 on the plasma DHT concentration was approximately $50 \%$ reduction of the basal value at steady-state of minimum TF-505 plasma concentration $\left(C_{\mathrm{ss}, \mathrm{min}}\right)$. Figure 6 was shown the maximum effect of TF-505 on DHT concentration reached $12 \mathrm{~h}$ after TF-505 administration. The fit value of $I_{\max }$ was 0.706 (Table 4), which suggests that a sufficient range of DHT inhibition was generated by the study to allow meaningful estimation of $\mathrm{PD}$ parameters.

It has been thought that PK-PD modeling involving the 
population approach is valuable through drug development, particularly from the early-phase studies with healthy people, to assess the efficacy and tolerability and to gain information about dosage regimen in the generalized or specific population. ${ }^{28)}$ Although the early human studies usually consist of small groups, for instance, in the present study 6 people each participated in each parallel dose group of single- and multiple-dose studies, individual person has extensive concentration-time profiles of the administered drug under the wellcontrolled experimental condition. In addition, as TF-505 has a surrogate endpoint to evaluate its pharmacological effect, pharmacodynamic information was also obtained. Thus, PK-PD modeling was performed on the full data sets after combining those small numbers of subjects to get more accurate information of population parameters estimates. In results, a good agreement of population parameters estimates with actual data was observed in the present study (Figs. 4, 5 ). As the ages of the participants in this population ranged from 20 to 64 years and older men will be susceptible to prostate hypertrophy, the $\mathrm{PK} / \mathrm{PD}$ model and parameters obtained in the present study are considered as representative of such populations.

Therefore, it is expected that those model and parameters estimates could be the basis to define possible clinical dosage regimen in patients in the following exploratory clinical studies and compare the potency of drug action with those of other similar drugs in vivo. However, there are some problems in application of those parameters to clinical phases, for possible differences in PK and PD between healthy people and patients and probable differences in present and clinical endpoints to evaluate drug efficacy.

In conclusion, the present study presents a successful population PK-PD model by incorporating a circadian rhythm in the early human study. The population parameters thus obtained could provide useful indicators for the determination of dosage regimens in patient populations and the defined PK/PD model could be applied to such populations.

\section{REFERENCES AND NOTES}

1) Present address: College of Pharmacy, Nihon University; 7-7-1 Narashinodai, Funabashi, Chiba 274-8555, Japan.

2) Thigpen A. E., Silver R. I., Guileyardo J. M., Casey M. L., McConnell J. D., Russell D. W., J. Clin. Invest., 92, $903-910$ (1993).

3) Brendler C. B., Follansbee A. L., Isaacs J. T., J. Urol., 133, 495-501
(1985).

4) Bruchovsky N., Rennie P. S., Batzold F. H., Goldenberg S. L., Fletcher T., McLoughlin M. G., J. Clin. Endocrinol. Metab., 67, 806-816 (1988).

5) Hudson R. W., Wherrett D. J., Steroid Biochem., 35, 231-236 (1990).

6) Andersson S., Berman D. M., Jenkins E. P., Russell D. W., Nature (London), 354, 159-161 (1991).

7) Imperato-McGinley J., Guerrero L., Gautier T., Peterson R. E., Science, 186, 1213-1215 (1974).

8) Fujita T., Matsumoto Y., Kimura T., Yokota S., Sawada M., Majima M., Ohtani Y., Kumagai Y., Br. J. Clin. Pharmacol., 54, 283-294 (2002).

9) Beal S. L., Sheiner L. B., "NONMEM Users' Guide," NONMEM Project Group, University of California, San Francisco, 1988.

10) Sjoberg B., de la Torre B., Hedman M., Falkay G., Diczfalusy E., J. Endocrinol. Invest., 2, 131-137 (1979).

11) Guignard M. M., Pesquies P. C., Serrurier B. D., Merino D. B., Reinberg A. E., Acta Endocrinol., 94, 536-545 (1980).

12) Zhou H., Choi L., Lau H., Bruntsch U., Vries E. E., Eckhardt G., Oosterom A. T., Verweij J., Schran H., Barbet N., Linnartz R., Capdeville R., J. Clin. Pharmacol., 40, 275-283 (2000).

13) Schmith V. D., Fiedler-Kelly J., Phillips L., Grasela T. H., Jr., Pharm. Res., 14, 91-97 (1997).

14) Williams P. J., Lane J. R., Turkel C. C., Capparelli E. V., Dziewanowska Z., Fox A. W., J. Clin. Pharmacol., 41, 259-267 (2001).

15) Zannikos P. N., Rohatagi S., Jensen B. K., DePhillips S. L., Rhodes G. R., J. Clin. Pharmacol., 40, 1129-1140 (2000).

16) Cullberg M., Eriksson U. G., Larsson M., Karlsson M. O., Br. J. Clin. Pharmacol., 51, 71-79 (2001).

17) Ploeger B., Mensinga T., Sips A., Deerenberg C., Meulenbelt J., DeJongh J., Toxicol., Appl. Pharmacol., 170, 46-55 (2001).

18) Guan F., Ishii A., Seno H., Watanabe-Suzuki K., Kumazawa T., Suzuki O., Anal. Chem., 71, 4034 - 4043 (1999).

19) Hosaka M., Konno M., Mamiya T., Nishimura R., Makino T., Folia. Endocrinol. Jap., 49, 1391-1393 (1973).

20) Jusko W. J., Ko H. C., Clin. Pharmacol. Ther., 56, 406-419 (1994).

21) Wyska E., Jusko W. J., Semin. Perinatol., 25, 124-132 (2001).

22) Katashima M., Irino T., Shimojo F., Kawamura A., Kageyama H., Higashi N., Miyao Y., Tokuma Y., Hata T., Yamamoto K., Sawada Y., Iga T., Clin. Pharmacol. Ther., 63, 354-366 (1998).

23) Ebling W. F., Matsumoto Y., Levy G., Pharm. Res., 13, 1804-1810 (1996).

24) Chakraborty A., Krzyzanski W., Jusko W. J., J. Pharmacokinet. Biopharm., 27, 23-43 (1999).

25) Gisleskog P. O., David H., Hammarlund-Udenaes M., Karlsson M. O., Clin. Pharmacol. Ther., 64, 636-647 (1998).

26) Tian G., Mook R. A., Jr., Moss M. L., Frye S. V., Biochemistry, 34, 13453-13459 (1995).

27) Ko H. C., Jusko W. I., Pharmacotherapy, 15, 509-511 (1995).

28) Vozeh S., Steimer J. L., Rowland M., Morselli P., Mentre F., Balant L. P., Aarons L., Clin. Pharmacokinet., 30, 81—93 (1996). 